\title{
Disaster Communication Study on Instagram Account @infobmkgmaluku of Ambon Earthquake 2019 Case
}

\author{
$1^{\mathrm{st} *}$ Beatriz Bridget Tanasale \\ Communication Studies \\ Universitas Indonesia \\ Jakarta, Indonesia \\ e-mail: beatriztanasale.academia@gmail.com
}

\author{
$2^{\text {nd }}$ Sari Monik Agustin \\ Communication Department \\ Universitas Multimedia Nusantara \\ Jakarta, Indonesia \\ e-mail: sarimonikagustin@gmail.com
}

\begin{abstract}
Social media is a popular tool of communication to use as a sharing content platform. Many people use it as their media, but little do we know that the government nowadays use it as a tool to engage their public, especially at crisis and disaster. This article describes the analysis of how local government organizations used social media during the Earthquake disaster as a tool to communicate with the public. Indonesia's national Meteorology Climatology and Geophysics council have been used social media to connect with the audience. In the case of Ambon Earthquake 2019, the organization uses local agency social media to communicate. The article finds that there is a high number of the Instagram user responding @infobmkgmaluku post during the disaster; also, the analysis shows there is a relation between the earthquake magnitude and user response.
\end{abstract}

Keywords-Disaster Communication, Social Media, Instagram

\section{INTRODUCTION}

Indonesia, located within the Ring of Fire area, it makes Indonesian regions vulnerable to earthquake disasters. 6000 earthquakes happened in Indonesia yearly (Ali, 2018). Indonesia National Council of Meteorology Climatology and Geophysics records that each year earthquake events always increase. On September 26th, 2019, the Maluku Province was shaken by an earthquake with a magnitude of 6.8. The location of the epicenter was at a distance of $42 \mathrm{~km}$ northeast of Ambon, the capital city of Maluku Province. After the Earthquake that occurred on the date, up to October 23rd, there were 1,802 aftershocks (Hidayat, 2020). In 2019, Ambon island experienced 5000 earthquake events, and the number is $44.06 \%$ of the 2019 earthquake that occurred in Indonesia (Assaudi, 2020). Compared to other disasters, Earthquake is a type of disaster that requires speed and accuracy in delivering information to the public because the event is unpredictable and can cause a Tsunami (Noor, 2014). Social media is a term to describe technology with the capability to create and share content to virtual networks and communities (Obar \& Wildman, 2015), various research has found that public and government used social media as a medium to communicate during the disaster (Lachlan et al., 2016). @infobmkgmaluku Instagram account is run and managed by the local government organization of Meteorology, Climatology, and Geophysics Council (Badan Meteorologi, Klimatologi dan
Geofisika/BMKG) for Maluku Province. The organization plays essential roles in communicated information on Earthquake events because they have the assets and technology to detect Earthquakes events in Indonesia and an early warning system. This Article focused on disaster communication mediated by social media during the Ambon Earthquake 2019 to show how the local organization of BMKG and Instagram user communicates during disaster through social media.

\section{METHOD}

This research using a content analysis method to analyze the data, with both quantitative research approaches to issue a general analysis of disaster communication that happened in the @infobmkgmaluku Instagram account, while the qualitative approach is used for in-depth analysis about specific things that need to be discussed. The data is limited to@infobmkgmaluku first week post of the Ambon earthquake. The data population is 187 Instagram posts, start from September 26th, 2019, post about 6.8 RS Earthquake to the last post of date, October 2nd, 2019

\section{FINDINGS AND DISCUSSIONS}

\section{A. Localized Information}

@infobmkgmaluku is run and managed by the local Meteorology, Climatology, and Geophysics Council for Maluku Province. The national council had their own Instagram account @infobmkg, who run and managed by the central organization in Jakarta. The national council's Instagram account, @infobmkg, contains all the information on Meteorology, Climatology, and Geophysics activity that happened in every area in Indonesia. At the same time, @infobmkgmaluku only provides information related to Maluku Province Meteorology, Climatology, and Geophysics activity. At the time of crisis, it is more useful for a centralized message to be communicated by local entities (Liu, Jin, Briones, \& Kuch, 2012).

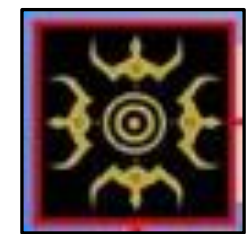

Fig. 1. Figure 1 Nunusaku Symbol 
In the post, we can find a local Maluku custom symbol, the symbol of Nunusaku. The symbol carries a value of "Esa ta na, Esa aman, Esa lala" which means human harmony life with God, Other people, and Nature (Sopamena, 2006). The symbol shows the connections and identities of the local communication that the organization wants to make with the local people of Maluku. In the same period (September 26th - October 2nd, 2019), @infobmkg create 22.5\% (9 out of 40) Instagram posts about Ambon Earthquake. Four posts about the realtime Earthquake and five posts of earthquake summary. From September 30th - October 2nd, 2019, there is no post about Ambon Earthquake, so it is not eligible for the public to used @infobmkg as a source of realtime Earthquake information. To reach a specific audience in this case, people that are impacted by Ambon Earthquake the organization used their local representations Instagram account.

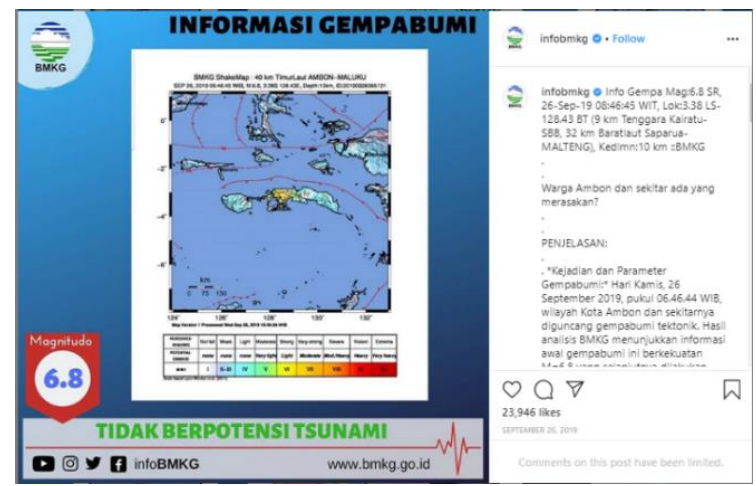

Fig. 2. Central Bureau of Meteorology, Climatology, and Geophysics Instagram post.

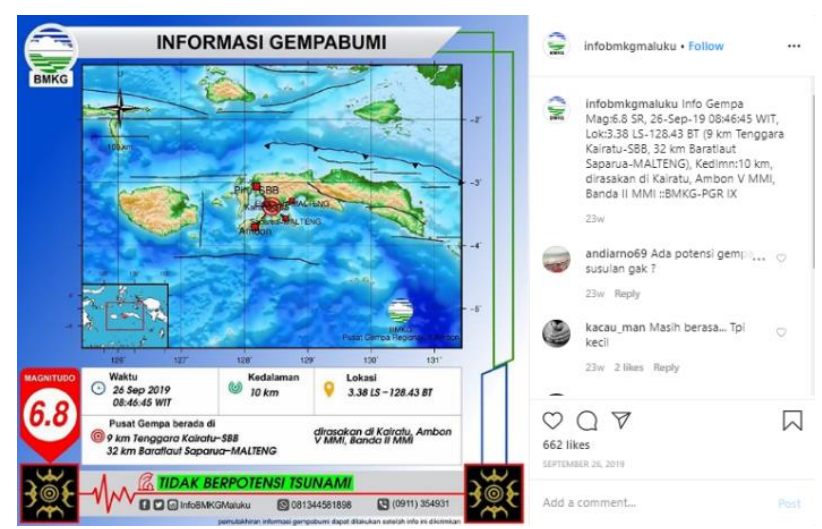

Fig. 3. Figure 2 Local Bureau of Meteorology, Climatology, and Geophysics Instagram post

The difference in the information that the public can get from both of the Instagram accounts is that people can get more details in @infobmkg. Besides the information about an earthquake that happened, the post also provides additional information such as the cause, the expert analyzes, and further suggested action to people in the area. All the extra information is written in the caption of the post. The local representation did not replicate the same message in their Instagram post. It means there is no social media standard and guidelines from topdown the organizations. Meanwhile, it is important in times of disaster for the public to get consistent messages and communications.

\section{B. Content}

Instagram can provide audio and visual content; from the data that we've been collecting, all the data population used picture and text as the medium to communicate. The data show that the content of the post divided into three types of content:

\section{1) Earthquake Information}

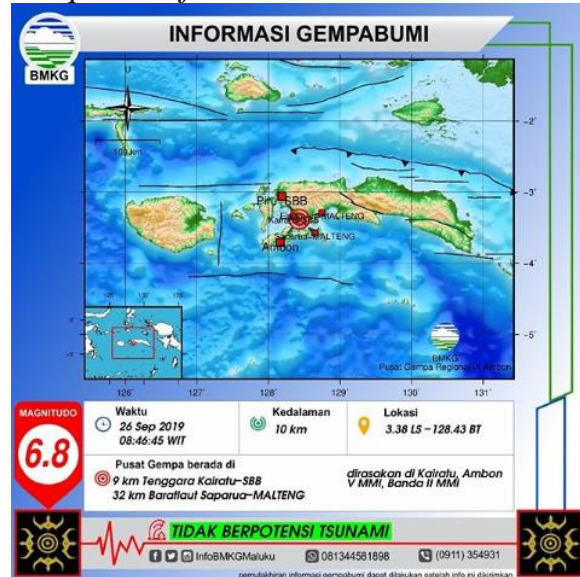

Fig. 4. Figure 3. @infobmkgmaluku post

98\%@infobmkgmaluku Instagram post population is a picture of location and information about the Earthquake (figure). The caption of the post is basically the written text of the earthquake information inside the image.

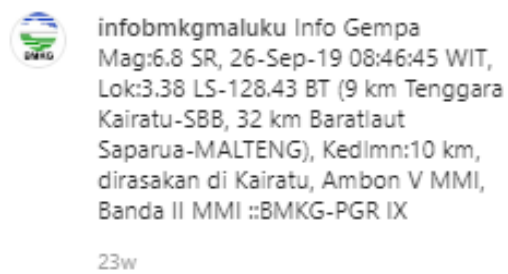

Fig. 5. Figure 4. @infobmkgmaluku caption

From the post, we can get information about the Earthquake that is happened, such as

- Time

- Map coordinates to locate the center of the eartquake

- The distance between the center of an earthquake to the nearest island/place

- Tsunami Potential. An earthquake can cause a Tsunami so it is important for the organization to inform the prediction.

- Local BMKG Maluku Call center and social media,

- Earthquake Magnitude in Richter Scal

- Modified Mercalli intensity scale (MMI). An information about intensity of the earthquake

Real data from BMKG tells that from September $26^{\text {th, }}$ 2019 - October $2^{\text {nd, }} 2019,968$ Earthquake event happened with 91 events is felt by people (measured by MMI scale). @infobmkgmaluku reports 183 events. All the activity that contains the MMI Scale is reported to the public in the @infobmkgmaluku Instagram account. 
2) Resume of Earthquake series

In the first week of the Ambon earthquake 2019, 3 data show a picture with a chart that is a summary of the earthquake event that happened during a certain period of time (fig.5). The resume in the form of a table can show the exact number of earthquake events that happened, whereas we found that some information might be or not reported on Instagram

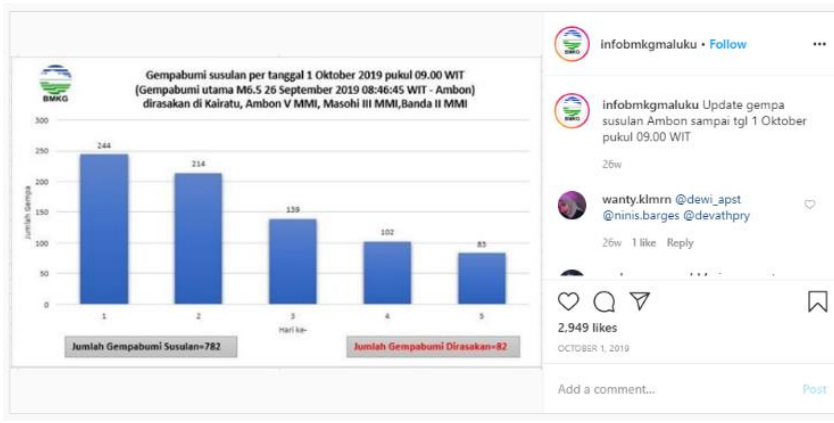

Fig. 6. Figure 5. Top user engagement post

\section{3) Press Release.}

There is only one Instagram content that contains a picture of official press release letter from Meteorology, Climatology, and Geophysics National Council in Jakarta, uploaded on September 27th, 2019. The post contains no caption to explain the picture, and the letter on the image carries two messages:

- Information about the number of earthquakes and the tendency to decrease earthquake activity.

- The organization clarifying hoaxes about the earthquake and tsunami predictions in the future, as well as calls for people to only trust official information from BMKG and government organizations.

\section{Instagram user Engagement and Activity During Disaster}

Instagram Engagement is an Instagram user involvement measured by Like or Comment activity on a post. Like and Comment is the way other users interact and react with the account trough a post. The statistic shows that the average number of Instagram user engagement is 969 per post. This number can also reflect the number of users that interact with the account.

\section{TABLE I. TABLE I INSTAGRAM USER ENGAGEMENT}

\begin{tabular}{|l|c|c|c|}
\hline \multirow{2}{*}{ Date } & \multicolumn{3}{|c|}{ Instagram Engagement per day } \\
\cline { 2 - 4 } & Total Post & $\begin{array}{c}\text { Comment+Like } \\
\text { Total }\end{array}$ & $\begin{array}{c}\text { Average } \\
\text { Engagement }\end{array}$ \\
\hline Sept $26^{\text {th }} 2019$ & 73 & 19398 & 265.7 \\
\hline Sept $27^{\text {th }} 2019$ & 36 & 31066 & 862.9 \\
\hline Sept $28^{\text {th }} 2019$ & 23 & 33776 & 1468.5 \\
\hline Sept $29^{\text {th }} 2019$ & 11 & 20405 & 1855 \\
\hline Sept $30^{\text {th }} 2019$ & 15 & 24965 & 1664.3 \\
\hline Oct $1^{\text {st }} 2019$ & 12 & 22298 & 1858.1 \\
\hline Oct $2^{\text {nd }} 2019$ & 17 & 29360 & 1727 \\
\hline
\end{tabular}

The table shows Instagram engagement from all 187 @infobmkgmaluku posts, and from the table, we can conclude that there is an increase in Instagram user engagement towards @infobmkgmaluku.
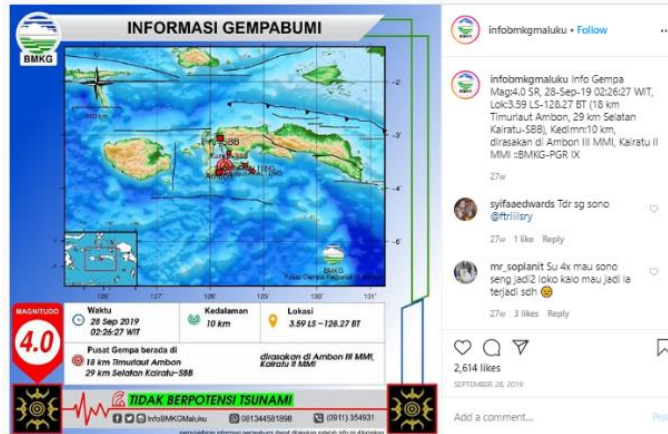

Fig. 7. Figure 6. Most comment post

A comment is an Instagram user interaction that is formed in the text so it can make an explicit response context that the user wants to show towards a post and to the account itself., or they make a reponse to other user comments. The most commented post (fig.6) shows that the earthquake event happened at 02:26 Am with a 4.0 RS and III MMI scale.

1) Relation Between Earthquake Magnitude and User Engagement.

To show the relations Between Earthquake Magnitude and Instagram user Engagement towards @infobmkgmaluku, from the 187 total of data population, we selected 66 posts of content that contains MMI (Modified Mercalli Intensity) number. It means that the information is based on an earthquake event with an intensity of shaking produced by an earthquake.

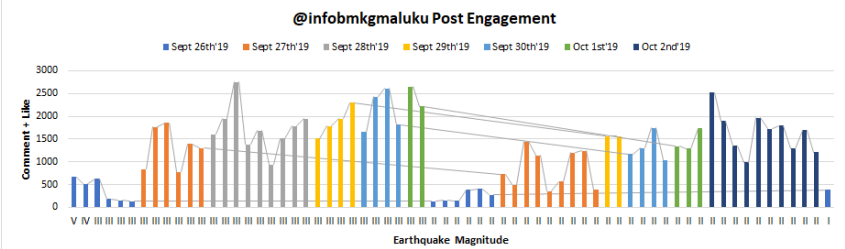

The $y$-axis shows the total number of Instagram user activity towards the post (Comment+Like). Data on the $\mathrm{x}-$ axis are sorted from big to small Earthquake magnitude MMI and The Richter magnitude scale.

The chart shows there is some inconsistency in the trends, but overall trends show that the engagement is lower when the earthquake magnitude is smaller. The figure shows that each day the number of Instagram engagement is increased. The dropping number on September 30th and October 2nd are happened because of that day most of the Earthquake with MMI Scale located in Kairatu, and not Ambon. It indicates that most of the use. who interacts with the account is mostly looking for information about Ambon and not Kairatu.

\section{Social Media User Respons}

The comment section can provide insight about Instagram user respond to the post or to the account, because 
of the writing expression can show the context and intention they try to make. We categorize the response to :

\section{1) Hoax Clarification}

From day 1 to day 7, we can found Instagram users responding to the post by asking for hoax clarification. The Instagram user considers the @infobmkgmaluku as a trusted source of information during a disaster, and since social media is two-way communication media, the user expects to get an answer from the organization through this account.

\section{2) Uncertainty Reduction}

Social media can connect people without distance limit. During the disaster, not only Instagram users who directly impacted by the Earthquake, people who not affected responding to the post, and asking about their friends and family that happened to live around the province. The post will reduce their uncertainty since someplace lose phone call signal, so it is impossible for them to reach their friends and family, they can use the

$$
\text { a) Pray }
$$

User shares their pray and thought in the account, hoping that the disaster will be passed.

From all the data population, there is no feedback from @ infobmkgmaluku to all user responses in comment sections. The only feedback besides earthquake information is the press release post.

\section{CONCLUSIONS}

Meteorology Climatology and Geophysics Council using Social media, which is an interactive platform as a medium to communicate with the public, but there is no interaction that Meteorology Climatology and Geophysics Council do with the Instagram user. The organizations treat Instagram as a one-way media that makes no difference from then other media that they own (websites and applications). The message form is consistent but lack of variation information such as instruction and hoax clarification. There is a tendency of Instagram users use @infobmkgmaluku as a credible source of information. Based on high user engagement data, it is shown that people use social media to seek information during a disaster. When the Earthquake magnitude is bigger, the engagement is relatively higher.

The way the organization focused on communicating with the public through their local organization is shown a positive outcome, but they might need a local approach more than just a symbol; for example, the language on writing captions. There is no standard, and guidelines make there is no consistency in the message that the national council and local organization make.

\section{REFERENCES}

[1] Ali, M. (2018, January 25). BNPB: Dalam Setahun, Indonesia Diguncang 6.000 Kali Gempa. Retrieved from https://www.liputan6.com/news/read/3236506/bnpb-dalamsetahun-indonesia-diguncang-6000-kali-gempa

[2] Hidayat, M. A. (2020, February 11). BMKG: Gempa Susulan di Ambon Sudah 3.089 Kali sejak September 2019. Retrieved from https://www.vivanews.com/berita/nasional/35819-bmkg-gempasusulan-di-ambon-sudah-3-089-kali-sejak-september2019?medium=autonext
[3] Lachlan, K. A., Spence, P. R., Lin, X., Najarian, K., \& Del Greco, M. (2016). Social media and crisis management: CERC, search strategies, and Twitter content. Computers in Human Behavior, 54, 647-652

[4] Noor, D. (2014). Pengantar Mitigasi Bencana Geologi. Deepublish.

[5] Obar, J. A., \& Wildman, S. S. (2015). Social media definition and the governance challenge: An introduction to the special issue.

[6] Sopamena, P. (2016). Etnomatematika Masyarakat Maluku Tengah dan Kota Ambon: Pemikiran Matematika dalam Multikultural. Matematika dan Pembelajaran, 4(2), 1-20. 